\title{
Đạo đức công vụ và mối quan hệ giữa đạo đức công vụ và pháp luật công vụ - Một số khía cạnh lí luận
}

\author{
Phạm Hồng Thái ${ }^{1}$, Phạm Thị Giang ${ }^{2, *}$ \\ ${ }^{1}$ Khoa Luật, Đại học Quốc gia Hà Nội, 144 Xuân Thủy, Cà̀u Giấy, Hà Nội, Việt Nam \\ ${ }^{2}$ Khoa Khoa học Hành chính \& Tổ chức nhân sư, Học viện Hành chính Quốc gia, \\ 77 Nguyễn Chi Thanh, Đống Đa, Hà Nội, Việt Nam \\ Ngày nhận 10 tháng 8 năm 2018 \\ Chỉnh sửa ngày 11 tháng 9 năm 2018; Chấp nhận đăng ngày 28 tháng 9 năm 2018
}

\begin{abstract}
Tóm tắt: Đạo đức công vụ và pháp luật công vụ là những hiện tượng, những bộ phận cấu thành văn hóa công vụ, có quan hệ mật thiết, tác động qua lại với nhau tạo thành một chỉnh thể thống nhất nhằm điều chỉnh hành vi cổng vụ của cán bộ, công chức. Bài viết luận bàn về đạo đức công vụ và mối quan hệ giữa đạo đức công vụ với pháp luật về công vụ thông qua phân tích về sự thống nhất, không thống nhất, khác biệt và sự tác động qua lại giữa các hiện tượng này.
\end{abstract}

Tù khóa: Đạo đức công vụ, mối liên hệ, pháp luật công vụ.

\section{Quan niệm về đạo đức và đạo đức công vụ}

\subsection{Quan niệm về đạo đức}

Lúc sinh thời Chủ tịch Hồ Chí Minh đã từng khẳng định: "Vì lẽ sinh tồn cũng như mục đích của cuộc sống, loài người mới sáng tạo và phát minh ra ngôn ngữ, chữ viết, đạo đức, pháp luật, khoa học, tôn giáo, văn học, nghệ thuật, những công cụ cho sinh hoạt hàng ngày về mặc, ăn, ở và các phương thức sử dụng" [1]. Ở đây, Chủ tịch Hồ Chí Minh đã khẳng định đạo đức các quy tắc, sản phẩm sáng tạo, vì cuộc sống của con người.

\footnotetext{
* Tác giả liên hệ. ĐT.: 84-986859988.

Email: vinhgiang2018@gmail.com https://doi.org/10.25073/2588-1167/vnuls.4174
}

Trong thời đại ngày nay tồn tại nhiều quy tắc xã hội: chính trị, pháp luật, đạo đức, tôn giáo, quy tắc của các tổ chức xã hội, cộng đồng,... Tất cả những quy tắc này tạo nên thể chế điều chỉnh quan hệ xã hội, chúng có quan hệ tác động qua lại lẫn nhau, tạo thành một chỉnh thể các nhân tố điều chỉnh hành vi, cách xử sự của con người, trong đó pháp luật luôn tỏ ra có ưu thế nhất định so với các quy phạm khác bởi tính quy phạm, tính phổ biến, bắt buộc thực hiện và các chức năng của nó.

Đạo đức được hiểu là "Phép tắc về quan hệ giữa người với người, giữa cá nhân với tập thể, với xã hội" [2], hay đạo đức chỉ nét đẹp, văn hóa của con người, "phẩm chất tốt đẹp của con người: sống có đạo đức". Trong ngôn ngữ tiếng Việt, đạo đức là từ ghép, được tạo bởi hai thành tố "đạo" và "đức"; "đạo" là "một cái đạo lí, một 
cái lẽ nhất định, là ai cũng phải noi đấy mà theo"; "đức" có nghĩa là "cái đạo để lập thân, thiện, làm thiện, cảm hóa đến người" [3] .

Như vậy, đạo đức được hiểu ở một số phương diện sau: thứ nhất, đạo đức là những chuẩn mực, những quy tắc hành vi, cách xử sự giữa con người với con người, do con người sáng tạo nên qua sự phát triển lịch sử của mình; thứ hai, đạo đức là công lí, lẽ phải, chuẩn mực phù hợp với quy luật của tự nhiên và cuộc sống của con người, là "cái lẽ sống, lẽ phải, đạo ở đời"; thứ ba, đạo đức là phẩm chất, nét đẹp của con người. Đạo đức là cái lẽ, cái mà con người phải tuân theo, noi theo, là cái phải làm và cái không được làm.

Trong các mối quan hệ: $c a ́$ nhân $<=>c a ́$ nhân, cá nhân <=> cộng đồng, cá nhân $<=>$ dân tộc, cá nhân $<=>$ quốc gia, cá nhân $<=>$ nhân loại, cá nhân <=> tư nhiên. Trong các mối quan hệ đó, thì yếu tố đầu tiên là yếu tố con người. Đạo đức luôn gắn với con người, không có con người, quan hệ con người thì không có đạo đức, con người là trung tâm của mọi vấn đề về đạo đức, do đó đạo đức trước hểt là sản phẩm do con người sáng tạo nên, phục vụ con người, vì con người và là nhân tố điều chỉnh ý thức, hành vi con người. Đồng thời trong mối quan hệ đó, cũng nẩy sinh các loại đạo đức: đạo đức giữa cá nhân con người với con người, cá nhân với cộng đồng xã hội, mà cá nhân đó có quan hệ, đạo đức của cá nhân với dân tộc, quốc gia của mình, đạo đức của cá nhân con người với đồng loại của mình, đạo đức của cá nhân với thế giới tự nhiên - môi trường sinh tồn của con người.

Đạo đức có lịch sử hình thành rất lâu dài và được kiểm nghiệm, sàng lọc trong đời sống xã hội, trước hết hình thành trong nhận thức của con người và dần được mô hình hóa thành các quy tắc hành vi, quy tắc xử sự của con người, được thể hiện dưới nhiều hình thức khác nhau (văn nói, văn viết - văn bản, lối sống, nếp sống) truyền từ thế hệ này sang thế hệ khác.

Từ đây có thể hiểu: Đạo đức là một hình thái ý thức xã hội, là hệ thống các nguyên tắc, quy phạm hình thành một cách tụ nhiên trên co sở quan niệm về lẽ phải, sư công bằng, về điều thiện, cái ác trong đời sống xã hội của con người, nhóm người, tầng lớp xã hội, giai cấp, dân tộc, quốc gia, thể hiện ý chí, tâm tu tình cảm của ho, nhằm điều chỉnh quan hệ xã hội, $y$ thức, hành vi của con người và là căn cứ để đánh giá hành vi, cách ứng xử của con nguời với nhau, của con người với gia đình, nhóm người, cộng đồng, giai cấp, tầng lớp xã họi, dân tộc, quốc gia và với thiên nhiên, được thưc hiện một cách tư giác bởi niềm tin, lòng nhân ái của con người, bởi truyền thống và súc mạnh của du luận cộng đồng, xã hội.

\section{2. Đạo đức công vu}

Hoạt động công vụ chủ yếu do cán bộ, công chức thực hiện, do vậy khi luận bàn về đạo đức của cán bộ, công chức trong công vụ cũng chính là luận bàn về đạo đức công vụ.

Cán bộ, công chức là một hợp phần của cộng đồng xã hội, do đó đạo đức của họ hàm chứa các yếu tố: đạo đức của dân tộc mà họ xuất thân, đạo đức cộng đồng nơi mà họ sinh sống, đạo đức của gia đình mà họ sinh ra, đạo đức xã hội - thời đại của họ, đạo đức của người cán bộ, công chức mà nhà nước, xã hội yêu cầu đòi hỏi trong hoạt động công vụ. Như vậy, đạo đức của cán bộ, công chức là sự "tổng hòa" đạo đức của các mối quan hệ. Đồng thời đạo đức của cán bộ, công chức tùy thuộc vào những yêu cầu, đòi hỏi của nhà nước đối với đạo đức cần có của cán bộ, công chức trong hoạt động công vụ. Từ đây có thể nhận thấy đạo đức cán bộ, công chức vừa chứa đựng những yếu tố chung đạo đức của thành viên xã hội, đạo đức cán bộ, công chức với tư cách là một bộ phận đạo đức xã hội, đạo đức của người cán bộ, công chức cụ thể, đạo đức của cán bộ, công chức trong hoạt động công vụ. Vì chỉ khi thực thi công vụ thì đạo đức công vụ của họ mới được biểu hiện một cách đầy đủ nhất, đạo đức công vụ của cán bộ, công chức là một bộ phận đạo đức của người cán bộ, công chức. Đạo đức cán bộ, công chức thể hiện, xuất phát từ vị thế của người đó trong bộ máy nhà nước, xã hội, khác với đạo đức của một công dân trong xã hội. Với cách 
tiếp cận như vậy, đạo đức của cán bộ, công chức bao gồm hai phần: đạo đức công vụ và đạo đức của người đó ngoài công vụ, mỗi mặt có những đặc trưng riêng của nó, tạo thành một thể thống nhất đạo đức của người cán bộ, công chức.

Từ những vấn đề nói trên có thể hiểu: $Đ a ̣$ đức công vu là hệ thống các nguyên tắc, các quy tắc hành vi, xủ sư trong công vu, nhằm điều chỉnh thái độ, hành vi, cách xử sư, chức trách, bổn phận, nghĩa vu của cán bộ, công chức trong hoạt động công vu và nhũng người khác khi được uỷ quyền thực thi công vu (tù khía canh chủ quan). Ngoài pham vi công vu thi đạo đức của cán bộ, công chức nhà nước không trờ thành đạo đức công vụ. Tù góc độ khách quan, đạo đức công vu của cán bộ, công chức là thái độ, hành vi, cách xủ sư, việc thực hiện chức trách, bổn phận, nghĩa vu của cán bộ, công chức khi thi hành công vu.

\section{Những tiêu chí để đánh giá đạo đức công vụ}

Tiêu chí đánh giá đạo đức công vụ là những chuẩn mực, căn cứ làm cơ sở để đánh giá đạo đức của người cán bộ, công chức khi thực thi công vụ. Việc hình thành các tiêu chí đánh giá đạo đức công vụ trước hết phải xuất phát từ quan điểm xây dựng nhà nước pháp quyền xã hội chủ nghĩa của nhân dân, do nhân dân, vì nhân dân, những yêu cầu của nhà nước pháp quyền đối với tổ chức, hoạt động của bộ máy nhà nước, hoạt động công vụ của những người thực thi công vụ; các nguyên tắc hoạt động công vụ; thái độ, hành vi ứng xử của người thực thi công vụ đối với các khách hàng của họ trong hoạt động công vụ. Mặt khác, xuất phát từ những mối quan hệ giữa người thực thi công vụ với nhà nước, cơ quan, những người khác nơi họ làm việc, với đối tượng mà hoạt động công vụ của họ tác động tới. Xuất phát từ quan niệm như vậy, các tiêu chí đánh giá đạo đức công vụ của cán bộ, công chức bao gồm:

Một là: sụ trung thành của người thực thi công vu với nhà nước, chính thể, tổ chức.
Đây là tiêu chí đầu tiên và quan trọng nhất để đánh giá đạo đức công vụ của người thực thi công vụ. Tiêu chí này mang tính chính trị vì hoạt động công vụ đều hướng tới thực hiện những nhiệm vụ chính trị nhất định, không có hoạt động công vụ nào lại không mang nội dung chính trị. Do đó, một trong những phẩm chất đạo đức không thể thiếu của những người phục vụ nhà nước vào bất kỳ thời đại nào, trong bất kỳ chính thể nào đều phải trung thành với nhà nước, với chính thể mà mình phục vụ, trung thành với sự nghiệp của tổ chức - nơi mình phục vụ, luôn phấn đấu vì mục tiêu của tổ chức. Bởi chính sự phát triển của tổ chức là cơ sở, tiền đề mang lại những lợi ích, nguồn lực cho người phục vụ trong tổ chức. Đây không chỉ là tiêu chí để đánh giá cán bộ, công chức, đồng thời cũng là yêu cầu của nhà nước, cơ quan, tổ chức đối với những người thực thi công vụ. Vì vậy, người thực thi công vụ không thể phản bội lại tổ quốc, chính thể, cơ quan, tổ chức mà mình đang phục vụ.

Hai là: việc chấp hành Hiến pháp và pháp luật, quy chế làm việc trong thi hành công vụ.

Tiêu chí về tính hợp hiến, hợp pháp của hoạt động công vụ bắt nguồn từ yêu cầu xây dựng Nhà nước pháp quyền xã hội chủ nghĩa của nhân dân, do nhân dân, vì nhân dân, quản lí xã hội pháp luật và nguyên tắc pháp chế xã hội chủ nghĩa đã được ghi nhận trong Hiến pháp Việt Nam năm 1992 (đã được sửa đổi, bổ sung năm 2001). Hiến pháp năm 2013 tuy không sử dụng thuật ngữ pháp chế xã hội chủ nghĩa, nhưng tinh thần của nguyên tắc này được thể hiện dưới hình thức mới với quy định: Nhà nước được tổ chức và hoạt động theo Hiến pháp và pháp luật, quản lí xã hội bằng Hiến pháp và pháp luật (Điều 8).

Việc chấp hành hiến pháp, pháp luật của cán bộ, công chức trong hoạt động công vụ là tiêu chí đặc biệt quan trọng để đánh giá đạo đức công vụ của cán bộ, công chức, vì chính họ là những người thực hiện, áp dụng pháp luật để đưa ra các quyết định quản lí khác nhau, cả quyết định quy phạm và quyết định cá biệt và thực hiện những hành vi hành chính để thực hiện những quyết định đó. Vì vậy, có thể nói 
rằng việc thực hiện "Hiến pháp và pháp luật là thước đo đạo đức", sự chấp hành Hiến pháp, pháp luật là tiêu chí không thể thiếu để đánh giá đạo đức của cán bộ, công chức trong hoạt động công vụ, không chỉ trong công vụ mà cả trong cuộc sống. Cán bộ, công chức cũng như mọi đối tượng khác trong xã hội không chấp hành Hiến pháp, pháp luật, hay chấp hành một cách không nghiêm minh, thường xuyên, liên tục thì cũng khó có thể nói rằng người đó có đạo đức, vì Hiến pháp và pháp luật là khuôn mẫu về hành vi, xử sự đã được nhà nước thừa nhận chính thức, luôn không đối lập với đạo đức, các quy tắc đạo đức thấm đượm vào Hiến pháp, pháp luật, do đó chấp hành Hiến pháp và pháp luật cũng là chấp hành các giá trị đạo đức đã được pháp luật hóa.

Bên cạnh Hiến pháp, pháp luật, quy chế làm việc của cơ quan đơn vị cũng có vai trò, công dụng rất lớn trong củng cố pháp chế và kỷ luật, quan hệ trong công vụ. Quy chế làm việc của cơ quan điều chỉnh nhiều quan hệ trực tiếp liên quan tới quan hệ công vụ của công chức, đó là quan hệ giữa người lãnh đạo, quản lí cấp trên với cấp dưới, những người lãnh đạo, quản lí cùng cấp, giữa người lãnh đạo, quản lí với nhân viên, giữa nhân viên với nhân viên...

Ba là: hiệu quả hoạt động công vu của cán bộ, công chức.

Người cán bộ, công chức thực thi công vụ được nhà nước trả lương từ ngân sách nhà nước, thực chất là từ tiền thuế của nhân dân, do đó hoạt động công vụ của họ phải mang lại hiệu quả nhất định nhằm góp phần tạo ra những giá trị xã hội, hoặc đáp ứng các yêu cầu hợp pháp của công dân, cơ quan, tổ chức. Hiệu quả hoạt động công vụ, việc hoàn thành nghĩa vụ, nhiệm vụ công vụ của cán bộ, công chức là thước đo đánh giá sự phục vụ, cống hiến của họ đối với nhà nước, xã hội, do đó hiệu quả hoạt động công vụ phải được coi là một trong những tiêu chí cơ bản để đánh giá đạo đức công vụ của cán bộ, công chức.

Bốn là: tính trung thực, không thiên vị, vu lọi trong hoạt động công vu.
Trung thực là đức tính, phẩm giá cao quý của con người, là sự đối lập với lừa đảo, dối trá. Trung thực chỉ có một, còn lừa đảo, dối trá thì bao nhiêu cũng có thể nếu người ta muốn. Tính trung thực của con người trong đời sống quyết định sự đúng đắn, khách quan trong mọi quan hệ xử sự của con người, đặc biệt đối với cán bộ, công chức khi thực thi công vụ. Khi không trung thực trong cuộc sống, trong hoạt động công vụ sẽ dẫn đến những quyết định sai trái gây tổn hại cho nhà nước, xã hội, cá nhân, tổ chức. Chính sự không trung thực của cán bộ, công chức sẽ dẫn họ tới những vi phạm pháp luật trong công vụ, vì không trung thực người ta mới khai gian lí lịch, thành tích để được khen thưởng, phong hàm, cấp, không trung thực mới dẫn tới thiên vị, bè phái, vì không trung thực, vụ lợi nên mới có tình trạng tham nhũng chính trị, tham nhũng kinh tế, tham nhũng trong khu vực công, khu vực tư.

Năm là: quan hệ giữa cán bộ, công chức với đồng nghiệp.

Trong hoạt động công vụ hình thành nên các mối quan hệ chính thống giữa các cán bộ, công chức với nhau, từ đó hình thành nên tình cảm, thái độ của họ với nhau trong công vụ. Người cán bộ, công chức có đạo đức công vụ tốt là người phải biết thiết lập quan hệ với đồng nghiệp trong công vụ, phải biết chia sẻ kinh nghiệm, hợp tác, không chỉ biết hoàn thành nghĩa vụ công vụ của mình mà phải biết giúp đỡ đồng nghiệp hoàn thành nhiệm vụ, công vụ, có tinh thần, thái độ cầu thị, biết giúp nhau cùng phát triển, hoàn thiện để hoàn thành mọi nhiệm vụ chung.

Trong các chức vụ nhà nước, có những chức vụ cao thấp khác nhau, từ đó mà hình thành quan hệ giữa cấp trên với cấp dưới, giữa cấp dưới với cấp trên trong quá trình thực thi công vụ.

Chỉ trong hoạt động công vụ mới hình thành quan hệ giữa cấp trên và cấp dưới, quan hệ giữa người lãnh đạo, quản lí với người bị lãnh đạo, quản lí là do địa vị pháp lí của họ trong công vụ quyết định, người lãnh đạo, quản lí, người bị lãnh đạo, quản lí đều phải ý thức 
được điều này. Người lãnh đạo, quản lí có đạo đức công vụ phải là người gương mẫu chấp hành Hiến pháp, pháp luật, kỷ luật và biết yêu cầu, hướng dẫn cấp dưới thực hiện, đồng thời biết hướng dẫn, dẫn dắt cấp dưới trong công vụ, tạo mọi điều kiện thuận lợi để cấp dưới hoàn thành nhiệm vụ, công vụ, phải biết nêu gương trong công vụ và trong sinh hoạt, tôn trọng ý kiến cấp dưới, biết nghe ý kiến đúng của cấp dưới, biết đáp ứng những yêu cầu đòi hỏi hợp pháp, chính đáng của cấp dưới, quan tâm thường xuyên tới tư cách, động cơ và lợi ích của cấp dưới, biết tạo điều kiện cho cấp dưới phát triển trong chức nghiệp, có lòng vị tha vì con người trong hoạt động lãnh đạo, quản lí và trong xử lí những vi phạm trên cơ sở những chuẩn mực pháp luật.

Quan hệ giữa cấp dưới với cấp trên, nhân viên với người quản lí, lãnh đạo. Đối với cấp trên, nhân viên phải tôn trọng người lãnh đạo, quản lí, chấp hành mọi quyể định hợp pháp của người lãnh đạo, quản lí, hoàn thành mọi nhiệm vụ, bổn phận công vụ của mình và chịu trách nhiệm trước cấp trên, người lãnh đạo, quản lí về mọi quyết định, hành vi công vụ của mình. Tôn trọng người lãnh đạo, quản lí là tôn trọng người giữ các chức vụ mà nhà nước đã trao cho họ.

\section{Sáu là: tận tụy phuc vu khách hàng.}

Hoạt động công vụ làm hình thành rất nhiều mối quan hệ, quan hệ giữa những người thực thi công vụ với nhau, với công dân, cơ quan, tổ chức mà hoạt động công vụ hướng tới phục vụ và những đối tượng này trở thành khách hàng của nền công vụ. Mục tiêu của hoạt động công vụ là phục vụ nhà nước, xã hội và công dân, do đó trong quá trình hoạt động công vụ, người cán bộ, công chức phải tôn trọng nhân dân, lắng nghe ý kiến của dân, phải đặt mình vào vị trí của khách hàng để giải quyết các công việc của khách hàng. Đồng thời khi thực thi công vụ, cán bộ, công chức cần phải có thái độ lịch sự và công bằng, giải quyết công việc đúng pháp luật, không gây phiền hà, sách nhiễu, không vụ lợi, hết lòng, hết sức phục vụ khách hàng của mình, quan tâm đến đời sống của họ, thật sự gần gũi, hiểu biết nguyện vọng chính đáng của các khách hàng, khiêm tốn học hỏi nhân dân. Sẵn sàng lắng nghe ý kiến phê bình, góp ý của các khách hàng của mình.

Bảy là, sụ tự giác thực hiện nghĩa vu, trách nhiệm, bổn phận công vu.

Thái độ của người thực thi công vụ đối với việc thực hiện nghĩa vụ, trách nhiệm, bổn phận công vụ có ý nghĩa rất quan trọng trong việc đánh giá đạo đức công vụ của họ. Thái độ trong công vụ có ảnh hưởng tới chất lượng hoạt động công vụ, quan hệ của người thực thi công vụ với khách hàng của nền công vụ. Người thực thi công vụ có thể bằng lòng nhiệt tình, sự tự giác hoặc cũng có thể bằng thái độ thờ $o$, thiếu trách nhiệm. Vì vậy, cần coi thái độ thực hiện nghĩa vụ, trách nhiệm, bổn phận công vụ là một trong những tiêu chí để đánh giá đạo đức công vụ của người thực thi công vụ.

\section{Mối quan hệ giữa đạo đức công vụ và pháp luật về công vụ}

Mối quan hệ giữa đạo đức công vụ và pháp luật về công vụ [3] được xem xét trên cơ sở mối quan hệ giữa đạo đức và pháp luật: sự thống nhất, không thống nhất, khác biệt và sự tác động qua lại giữa chúng [4].

\subsection{Sư thống nhất giữa đạo đức công vu và pháp luật về công vu}

Sự thống nhất giữa đạo đức công vụ và pháp luật về công vụ thể hiện ở những điểm căn bản sau đây:

Thứ nhất, đạo đức công vụ và pháp luật về công vụ đều là những giá trị xã hội do con người sáng tạo nên và để phục vụ cho cuộc sổng của con người, đều là những nhân tố điều chỉnh các quan hệ xã hội, định hướng cho sự phát triển tiến bộ của các quan hệ xã hội hình thành trong công vụ, đều là những chuẩn mực hành vi, cách ứng xử của công chức trong hoạt động công vụ. Hai nhân tố này bổ sung cho nhau trong điều chỉnh các quan hệ phát sinh trong hoạt động công vụ. Pháp luật về công vụ không thể tồn tại nếu thiếu cơ sở đạo đức công vụ, đạo đức công vụ là nguồn vật chất của pháp 
luật về công vụ, nhưng đạo đức công vụ nếu thiếu pháp luật sẽ không có khả năng phát huy chức năng điều chỉnh các quan hệ phát sinh trong hoạt động công vụ.

Về mối quan hệ giữa đạo đức với pháp luật nói chung và cũng là mối quan hệ giữa đạo đức công vụ và pháp luật về công vụ, ông Vũ Đình Hòe có nhận xét rất xác đáng "Trong cái nhất thể "đạo đức - pháp luật" - xét về cội nguồn thì Thiện, Đức có trước và là gốc của Lễ, Luật; mà xét về công dụng đối với xã hội thì: đạo đức gây men sống, còn pháp luật là chuẩn, xác định mức độ phạm vi, phương pháp tác động của men sống ấy chỉ đạo hành động con người bảo đảm cho hành động ấy có hiệu quả đổi với xã hội" [5]. Với cách tiếp cận này thì thiện, đức chính là đạo đức là cái thứ nhất, có trước pháp luật, còn pháp luật là cái thứ hai được sản sinh trền nền đạo đức, đạo đức là lẽ sống, men sống của cuộc đời, tạo nên pháp luật, còn pháp luật là chuẩn mực hành vi của con người được xây dựng trên nền đạo đức, việc thực hiện pháp luật - chuẩn mực lại do đạo đức - yếu tố nội tâm của con người quyết định. Xét theo cách tiếp cận này thì đạo đức được đặt cao hơn pháp luật, là nền tảng của pháp luật, nhưng cũng không vì thế mà coi nhẹ pháp luật, tuyệt đối hóa đạo đức trong đời sống cộng đồng đầy phức tạp và rộng lớn như ngày nay.

Thứ hai, đạo đức công vụ và pháp luật về công vụ tồn tại là khách quan bổ sung, hỗ trợ trong điều chỉnh ý thức, hành vi, cách xử sự của cán bộ, công chức trong thực thi công vụ. Một người không chấp hành các quy tắc pháp luật trong hoạt động công vụ, cũng đồng thời có nghĩa là vi phạm các quy tắc đạo đức công vụ. Nhưng không đồng nhất giữa đạo đức công vụ với pháp luật về công vụ. Pháp luật về công vụ có những quy định độc lập, nằm ngoài phạm vi đạo đức công vụ.

Thứ ba, đạo đức công vụ và pháp luật về công vụ đều có vai trò và hướng tới mục tiêu chung là trật tự hóa, củng cố các quan hệ xã hội phát sinh trong đời sống nhà nước, xã hội và hoàn thiện đời sống xã hội, phát triển và làm giàu thêm nhân cách, bảo vệ quyền, tự do, lợi ích của con người, hướng con người tới chủ nghĩa nhân đạo, công lí, sự tự do, bình đẳng, lòng nhân ái. Trong mối quan hệ này, đạo đức công vụ, pháp luật về công vụ như là những hình thức thể hiện các giá trị xã hội, mà nhà nước cần phải gìn giữ, củng cố, bảo vệ.

Thứ tư, đạo đức công vụ và pháp luật về công vụ đều có đối tượng điều chỉnh là các quan hệ trong công vụ đều hướng tới những nhóm người, tầng lớp, giai cấp, tập thể, cộng đồng, quốc gia, dân tộc với những yêu cầu đòi hỏi như nhau. Thông qua chức năng điều chỉnh các quan hệ xã hội, pháp luật công vụ và đạo đức công vụ tạo thành một thể thống nhất các quy phạm xã hội.

Thứ năm, đạo đức công vụ, pháp luật về công vụ đều là những quy phạm, hiện tượng xã hội xác định ranh giới giữa cái cần phải và cái có thể, cái không thể trong các hành vi xử sự của các chủ thể quan hệ công vụ. Pháp luật về công vụ và đạo đức công vụ trở thành phương tiện thể hiện, thừa nhận các lợi ích cá nhân, xã hội.

Thứ sáu, đạo đức công vụ và pháp luật về công vụ là những giá trị xã hội, là những chỉ số văn hóa công vụ, văn hóa xã hội của sự tiến bộ xã hội, các nguyên tắc, kỷ luật trong đời sống nhà nước, xã hội. Đạo đạo đức công vụ và pháp luật về công vụ đều hướng tới thiết lập đời sống cộng đồng chung của con người.

Thứ bảy, sự thống nhất giữa đạo đức công vụ và pháp luật về công vụ thể hiện ở sự tác động qua lại giữa hai hiện tượng : (i) đạo đức công vụ là cơ sở, là nguồn sống của pháp luật công vụ, pháp luật về công vụ không bao giờ đối lập với các quy tắc đạo đức công vụ; (ii) pháp luật là phương tiện để ghi nhận, thể chế hóa các quan niệm, ý niệm, chuẩn mực đạo đức công vụ, biến chúng thành những chuẩn mực chung trong hoạt động công vụ, buộc mọi đối tượng tham gia quan hệ công vụ phải thực hiện. Bằng con đường này mà nhiều quy phạm đạo đức công vụ được "chuyển hoá" thành pháp luật về công vụ. Luật cán bộ, công chức năm 2008 có những quy định khái quát về đạo đức của cán bộ, công chức "Cán bộ, công chức phải 
thực hiện cần, kiệm, liêm, chính, chí công vô tư trong hoạt động công vụ" (Điều 15). Nội dung của "cần, kiệm, liêm chính, chí công vô tư" được cụ thể hóa thành các quy định về chế độ trách nhiệm, nghĩa vụ của cán bộ, công chức trong khi thi hành công vụ.

Như vậy, trong mối quan hệ này quy phạm pháp luật về công vụ trong một số trường hợp trở thành hình thức pháp lí thể hiện của những giá trị đạo đức công vụ, nói cách khác đạo đức công vụ là phạm trù nội dung, còn pháp luật về đạo đức công vụ là phạm trù hình thức, thể hiện nội dung đạo đức công vụ. Ngoài ra, đạo đức công vụ còn được thể hiện dưới hình thức quy phạm chính trị, quy phạm của các tổ chức xã hội,... Những chuẩn mực đạo đức công vụ được thể hiện dưới hình thức pháp luật thì chính chúng đã được chuyển hoá thành pháp luật và trong trường hợp này đạo đức không còn là đạo đức theo nghĩa nguyên thuỷ của nó, nó đã biến thể thành pháp luật.

\subsection{Sự không thống nhất giũa pháp luật công vu và đạo đúc công vu}

Pháp luật công vụ và đạo đức công vụ thống nhất với nhau, nhưng không thể đồng nhất giữa hai hiện tượng này, các quy phạm đạo đức công vụ "trở thành" các quy phạm pháp luật công vụ thông qua sự phê chuẩn, chấp nhận của nhà nước bằng hoạt động sáng tạo pháp luật của các cơ quan nhà nước, người có thẩm quyền. Thông qua đó mà một bộ phận các quy phạm đạo đức công vụ "trở thành" pháp luật về công vụ, trong trường hợp này pháp luật công vụ đã tiếp nhận đạo đức công vụ, pháp luật và đạo đức công vụ thống nhất, nhưng cũng có những trường hợp pháp luật lại không tiếp nhận đạo đức. Thực tiễn đã chỉ ra rằng trong bất kỳ một xã hội nào cả trong quá khứ và hiện tại vẫn còn tồn tại cả chuẩn mực đạo đức công vụ của nhà nước cũ trước đó không phù hợp với thời đại mới, sự tồn tại này là do ý thức đạo đức công vụ - một bộ phận hình thái ý thức xã hội thuộc về yếu tố chủ quan của con người, một chế độ nhà nước tuy không còn nhưng ý thức do xã hội, nhà nước đó sản sinh ra vẫn tồn tại dai dẳng mang cả tính tích cực và tiêu cực. Thời đại chúng ta đang sống - thời đại xây dựng nhà nước pháp quyền xã hội chủ nghĩa của nhân dân, do nhân dân, vì nhân dân, chế độ phong kiến ở nước ta đã bị đập tan, nhưng ý thức đạo đức công vụ do nó sản sinh ra vẫn còn tồn tại có cả mặt tích cực và tiêu cực. Mặt tích cực được phát huy, được pháp luật thừa nhận, củng cố, mặt tiêu cực bị lên án, không được pháp luật thừa nhận. Rõ ràng trong trường hợp này giữa pháp luật công vụ và một bộ phận đạo đức công vụ có phần lệch pha - pháp luật công vụ không dung nạp, không thừa nhận những quy tắc đạo đức công vụ đã lỗi thời, không còn phù hợp. Chế độ phong kiến đã sản sinh ra quan hệ "vua tôi", sự tôn sùng cá nhân. Tất cả những điều này đều không những không được pháp luật công vụ hiện nay chấp nhận mà còn bị lên án, phê phán bởi cán bộ, công chức và dư luận xã hội.

Sự không thống nhất giữa pháp luật công vụ và đạo đức công vụ còn thể hiện ở chỗ, trong pháp luật công vụ có những quy phạm thuần túy mang tính kỹ thuật - pháp lí, chẳng hạn những quy phạm quy định về tổ chức bộ máy nhà nước, nhiệm vụ, quyền hạn của các cơ quan nhà nước, nhiệm vụ, quyền hạn của cán bộ, công chức, những quy định về các thủ tục hành chính.

\subsection{Sự khác biệt giũ̃a pháp luật công vu và đạo đức công vu}

Sự khác biệt giữa pháp luật công vụ và đạo đức công vụ thể hiện ở những điểm căn bản sau đây:

Thứ nhất, pháp luật công vụ và đạo đức công vụ khác nhau bởi con đường hình thành và phát triển. Pháp luật công vụ do nhà nước ban hành, thừa nhận, đình chỉ, sửa đổi, bổ sung, bãi bỏ. Pháp luật và đạo đức có phạm vi điều chỉnh rộng hẹp, khác nhau, có những quan hệ được cả đạo đức công vụ và pháp luật về công vụ điều chỉnh, nhưng có những quan hệ công vụ chỉ do pháp luật về công vụ điều chỉnh. Đạo đức công vụ lại là sản phẩm chung của xã hội, hình thành rất lâu dài trong lịch sử có nhà nước, trong hoạt động thực tiễn, đời sống nhà nước, được chọn lọc tự nhiên qua nhiều thế hệ, được lưu truyền 
từ thế hệ này sang thế hệ khác. Đạo đức công vụ vừa mang tính phổ biến, lại vừa mang tính cá biệt, cụ thể của từng đối tượng cán bộ, công chức (đạo đức của công chức ở những ngành nghề khác nhau).

Thứ hai, pháp luật công vụ và đạo đức công vụ khác nhau bởi phương pháp bảo đảm thực hiện chúng. Nếu pháp luật được bảo đảm bởi các biện pháp mang tính nhà nước, không loại trừ phương pháp cưỡng chế nhà nước, thì đạo đức công vụ lại được bảo đảm bởi chính các dự luận trong cơ quan, tổ chức, dư luận xã hội, sự đáng giá của cộng đồng xã hội.

Thứ ba, pháp luật công vụ và đạo đức công vụ khác nhau bởi các tính chất đặc trưng, phạm vi tác động điều chỉnh của chúng đối với các quan hệ công vụ và vai trò của chúng đối với đời sống nhà nước, xã hội.

Thứ tư, pháp luật công vụ và đạo đức có các thuộc tính, hình thức thể hiện khác nhau.

Thứ năm, pháp luật công vụ và đạo đức công vụ tác động điều chỉnh tới ý thức, hành vi của con người bởi tính chất, phương thức khác nhau.

Thứ sáu, pháp luật công vụ và đạo đức công vụ khác nhau bởi tính chất, trình tự, thủ tục áp dụng các biện pháp trách nhiệm do vi phạm.

Thứ bảy, pháp luật công vụ và đạo đức công vụ khác nhau bởi mức độ các yêu cầu, đòi hỏi đối với hành vi của cán bộ, công chức trong hoạt động công vụ. Đạo đức công vụ bao giờ cũng có yêu cầu đòi hỏi cao hơn đối với hành vi của cán bộ, công chức so với pháp luật về công vụ. Nếu pháp luật về công vụ chỉ đặt ra yêu cầu, đòi hỏi "tối thiểu" đối với hành vi thì đạo đức đặt ra mức "tối đa" đối với hành vi của cán bộ, công chức trong hoạt động công vụ.

Thứ tám, dưới góc độ triết học thì đạo đức công vụ là một bộ phận của đạo đức nói chung, cùng với đạo đức của các đối tượng khác trong xã hội tạo thành hình thái ý thức xã hội cùng với các hình thái ý thức xã hội khác (chính trị, tư tưởng, khoa học và nghệ thuật...) còn pháp luật công vụ dưới góc độ pháp lí chỉ là những văn bản quy phạm pháp luật không phải là một hình thái ý thức xã hội, mà cả ý thức pháp luật mới tạo thành một hình thái ý thức xã hội.

\subsection{Sự tác động qua lại giữa pháp luật công vu và đạo đúc công vu}

Sự tác động qua lại giữa pháp luật công vụ và đạo đức công vụ được thể hiện ở những nội dung cơ bản sau đây:

Một là, sự tác động qua lại giữa pháp luật công vụ và đạo đức công vụ bắt nguồn từ sự tác động qua lại có tính xã hội và sự tác động chức năng của chúng. Pháp luật công vụ và đạo đức công vụ là hai nhân tố cơ bản điều chỉnh các quan hệ công vụ, chúng bổ sung cho nhau cùng nhau duy trì trật tự các quan hệ công vụ, cùng ảnh hưởng tới nhân cách cán bộ, công chức, hình thành văn hoá đạo đức, văn hóa công vụ, ý thức đạo đức và ý thức pháp luật của mọi cán bộ công chức. Chúng có nhiều những yêu cầu, đòi hỏi chung đối với các hành vi của các chủ thể vốn được pháp luật công vụ và đạo đức công vụ khuyến khích. Nếu pháp luật công vụ trừng phạt đối với những hành vi vi phạm pháp luật, đặc biệt những hành vi tội phạm, thì đạo đức công vụ lại là sự bàn luận, đánh giá, lên án những hành vi đó. Sự đánh giá của pháp luật công vụ và đạo đức công vụ thường là thống nhất. Mọi hành vi vi phạm pháp luật công vụ, về nguyên tắc đồng thời cũng là vi phạm đạo đức công vụ. Pháp luật công vụ quy định phải chấp hành các đạo luật, thì đồng thời cũng bổ sung vào đó đạo đức công vụ.

Hai là, đạo đức công vụ là cơ sở của pháp luật công vụ. Không một pháp luật nào lại không có cơ sở đạo đức của nó, không có pháp luật nào lại là pháp luật không đạo đức. Pháp luật về công vụ không thể tồn tại thiếu cơ sở đạo đức. Theo nghĩa này đạo đức công vụ là nguồn vật chất của pháp luật công vụ theo đúng nghĩa của từ này.

Ba là, đạo đức công vụ là cơ sở bảo đảm cho việc thực hiện đúng pháp luật công vụ trên thực tế. Từ góc nhìn pháp lí thì việc thực hiện pháp luật (tuân thủ, chấp hành, sử dụng và áp dụng pháp luật) là nghĩa vụ của các cán bộ, công chức, nhưng việc thực hiện trên thực tế 
nghĩa vụ đó lại tuỳ thuộc vào sự tự giác của cán bộ, công chức. Mà sự tự giác nhiều hay ít lại tuỳ thuộc ở ý thức đạo đức công vụ và ý thức pháp luật của cán bộ, công chức về bổn phận, trách nhiệm của mình đối với xã hội, nhà nước, đối với tổ chức và đối với các thành viên khác trong cộng đồng, xã hội.

Bốn là, mối quan hệ giữa pháp luật và đạo đức thể hiện qua sự tác động của pháp luật công vụ đối với đạo đức công vụ. Sự tác động này thể hiện ở những nội dung sau đây:

Thứ nhất, như đã nêu ở phần trên, nhà nước thừa nhận những quy tắc đạo đức công vụ tiến bộ và từng bước lựa chọn những quy tắc đạo đức công vụ tốt đẹp, lành mạnh, thể chế hoá thành các quy phạm pháp luật, nghĩa là chuyển hóa đạo đức công vụ thành những quy phạm pháp luật về công vụ. Thông qua sự chuyển hóa đó các quy phạm đạo đức công vụ trở thành các chuẩn mực thể hiện dưới hình thức pháp lí, được nhà nước bảo đảm thực hiện, mọi cán bộ, công chức phải tuân theo. Từ đó mà thực hiện pháp luật về công vụ có nội dung đạo đức cũng chính là thực hiện các quy tắc đạo đức công vụ. Chính sự chuyển hóa này mà hình thành mối quan hệ giữa pháp luật công vụ và đạo đức công vụ nhờ có sự điều chỉnh của pháp luật công vụ mà các quy phạm đạo đức công vụ ngày càng được củng cố, phát huy các giá trị của nó trong điều chỉnh quan hệ công vụ.

Thứ hai, nhà nước ban hành nhiều quy định pháp luật nhằm đề cao, bảo tồn, phát huy những giá trị đạo đức công vụ tốt đẹp đồng thời ngăn chặn những hành vi trái với đạo đức công vụ (xem hình).

Mối quan hệ giữa đạo đức công vụ và pháp luật công vụ được biểu thị bằng mô hình.

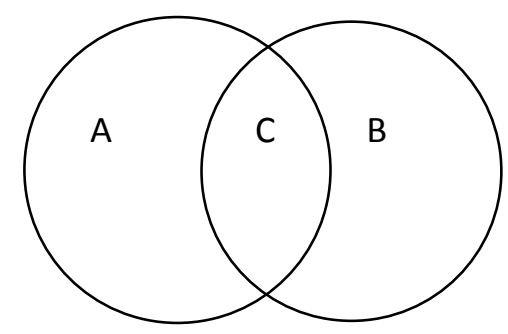

Vòng tròn $\mathrm{A}$ biểu thị các quy phạm pháp luật công vụ còn vòng tròn $\mathrm{B}$ biểu thị quy phạm đạo đức công vụ, phần $\mathrm{C}$ giao nhau biểu thị sự thống nhất giữa pháp luật công vụ với đạo đức công vụ. Phần còn lại của vòng tròn $\mathrm{A}$ biểu thị sự khác nhau của các quy phạm pháp luật công vụ với các quy phạm đạo đức công vụ. Điều này có nghĩa là có những quy phạm pháp luật công vụ không mang nội dung đạo đức công vụ, hoặc là pháp luật công vụ không chấp nhận một số quan niệm, ý niệm về đạo đức công vụ, ở đây bao gồm cả những quy phạm pháp luật không đánh giá những hành vi đạo đức của con người. Phần còn lại của vòng tròn $\mathrm{B}$ biểu thị các quy phạm đạo đức công vụ không nằm trong nội dung các quy phạm pháp luật công vụ, có nghĩa nó không được thể chế hóa thành pháp luật. Có thể được thể hiện trong các văn bản của tổ chức chính trị, chính trị - xã hội, tổ chức xã hội hoặc chưa được thể chế chính thức, đạo đức nằm trong ý thức của cán bộ, công chức. Chính vì vậy, có những hành vi vi phạm pháp luật về công vụ thì đồng thời cung vi phạm đạo đức công vụ, nhưng có hành vi vi phạm pháp luật lại không vi phạm đạo đức công vụ.

Tóm lại, đạo đức công vụ và pháp luật công vụ là những yếu tố điều chỉnh hành vi công vụ của cán bộ, công chức, có vai trò, giá trị khác nhau tạo nên văn hóa công vụ, có quan hệ mật thiết tác động qua lại lẫn nhau, tạo thành một chỉnh thể thống nhất các yếu tố điều chỉnh hành vi công vụ của cán bộ, công chức. Đạo đức công vụ là cơ sở để hình thành pháp luật công vụ, pháp luật công vụ trong những trường hợp nhất định là hình thức thể hiện của đạo đức công vụ, bên cạnh đó đạo đức công vụ còn được thể hiện trong các văn kiện của tổ chức chính trị, chính trị - xã hội, trong nhận thức của cán bộ, công chức, của xã hội. Các quy tắc đạo đức công vụ dần được pháp luật hóa thành các quy phạm pháp luật để điều chỉnh hành vi cách xử sự của cán bộ, công chức trong hoạt động công vụ trong quan hệ với đồng nghiệp, với khách hàng của nền công vụ - cá nhân, tổ chức. Đạo đức công vụ và pháp luật công vụ là những bộ phận cấu thành của văn hóa công vụ. 


\section{Tài liệu tham khảo}

[1] Hồ Chí Minh. Toàn tập. NXB. Chính trị Quốc gia. N. 2002. Tập 3, tr. 434.

[2] Đại từ điển Tiếng Việt (Nguyễn Như ý chủ biên), Nxb, Văn hóa - Thông tin. Hà Nội 1999, tr. 595.
[3] Thiền Chửu (2001), Hán Việt từ điển, NXB, Văn hóa Thông tin, HN, tr. 177, tr. 614.

[4] Xem: Pháp luật (Phạm Hồng Thái chủ biên), Pháp luật về công vụ và đạo đức công vụ, Nxb. Đại học Quốc gia HN, 2014, tr. 146; tr. 93 - 108.

[5] Vũ Đình Hòe, Pháp quyền - nhân nghĩa Hồ Chí Minh. NXB. Văn hóa Thông tin.H. 2001.tr. 334.

\title{
Relationship between Civil Service Ethics and Civil Service Law: Some Theoretical Issues
}

\author{
Pham Hong Thai ${ }^{1}$, Pham Thi Giang ${ }^{2}$ \\ ${ }^{1}$ VNU School of Law, 144 Xuan Thuy, Cau Giay, Hanoi, Vietnam \\ ${ }^{2}$ Faculty of Humanities and Administration, National Academy of Civil Administration, \\ 77 Nguyen Chi Thanh, Dong Da, Hanoi, Vietnam
}

\begin{abstract}
Civil service ethics and civil service law are the phenomena and the components of the civil service culture, which are closely related and interact with one another to form a unified system for regulating civil service behaviours of civil officials and employees. The article discusses the ethics of civil service and the relationship between civil service ethics and civilservice law by analysing the unity, disunity, difference and the interaction of these phenomena.
\end{abstract}

Keywords: Civil service ethics, relationship, civilservice law. 